\title{
Underwear fetishism induced by bilaterally decreased cerebral blood flow in the temporo-occipital lobe
}

Koji Masuda, Yoshinobu Ishitobi, Yoshihiro Tanaka, Jotao Akiyoshi

Department of Neuropsychiatry, Oita University Faculty of Medicine, Yufu-Shi, Oita, Japan

\section{Correspondence to} Dr Jotao Akiyoshi, akiyoshi@oita-u.ac.jp

Accepted 9 September 2014

CrossMark

To cite: Masuda $\mathrm{K}$, Ishitobi Y, Tanaka Y, et al. BMJ Case Rep Published online: [please include Day Month Year] doi:10.1136/ bcr-2014-206019

\section{DESCRIPTION}

Fetishism is a disease characterised by sexual arousal caused by inanimate objects, often including clothing such as pants, bras, and stockings and women's shoes. Patients with fetishism often show a strong interest in non-genital body parts.
Hypotheses based on biology, conditioning, social learning and psychoanalysis have been proposed to explain the underlying mechanism of fetishism. However, it is difficult to elucidate the aetiology of this rare disease on the basis of large-scale evaluations. We previously reported that hippocampal

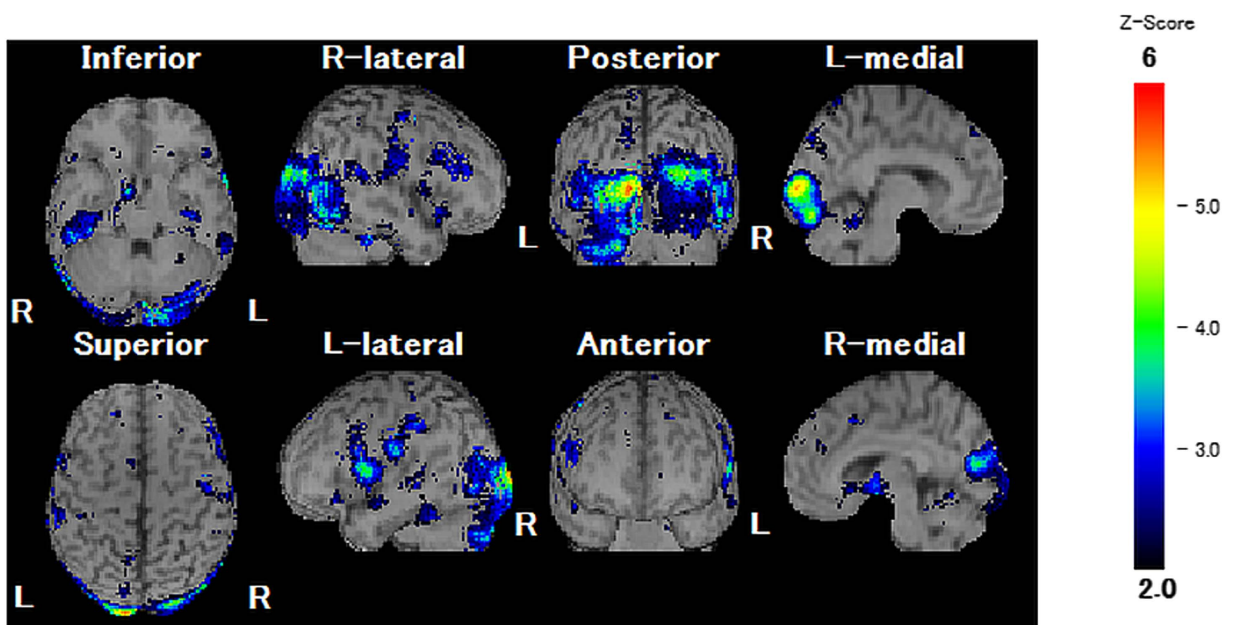

$\mathbf{R}$

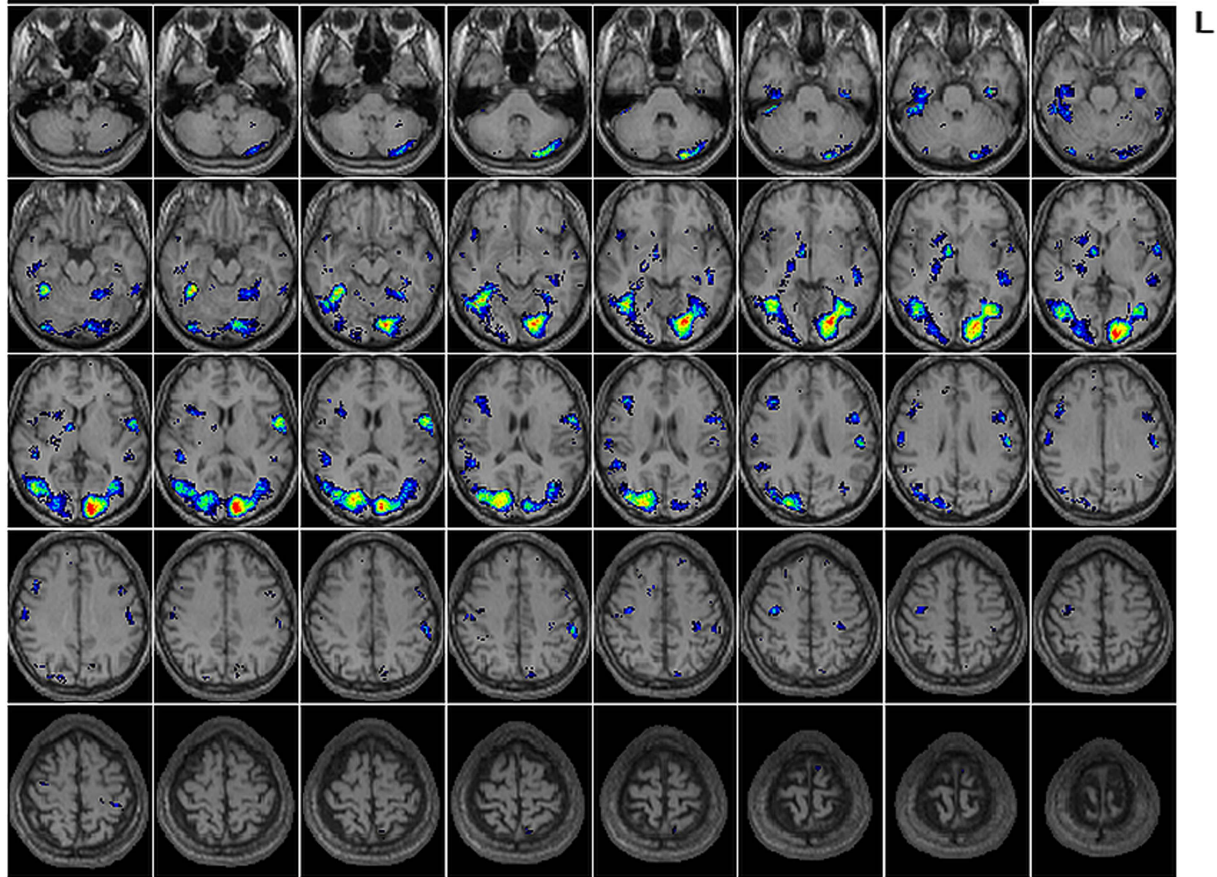

Figure 1 We performed single-photon emission CT (SPECT) imaging using 99 mTc-ECD as the tracer. We used proportional scaling to normalise the SPECT images and performed statistical analysis on a voxel-by-voxel basis using statistical parametric mapping (SPM8). The images were realigned, spatially normalised to a standard stereotactic space, which was based on the Montreal Neurological Institute template, and smoothed with an isotropic, $12 \mathrm{~mm}$, full-width half-maximum Gaussian filter to improve the signal-to-noise ratio. Using Student $t$ tests, we compared our SPECT data with those from 20 age-matched healthy controls that were drawn from a large database obtained from the National Center Hospital for Mental, Nervous, and Muscular Disorders. 
agenesis was associated with hypersexuality, considering that it was successfully treated with carbamazepine. ${ }^{1}$ A relationship between temporal lobe dysfunction and fetishism has been described previously. ${ }^{2}$ Few reports have described the association between fetishism and brain function. We examined this association using single-photon emission CT (SPECT) in a 24-year-old male patient who was arrested for stealing underwear and referred to our hospital for evaluation. The patient had stolen women's underwear on multiple occasions since the

\section{Learning points}

Fetishism can originate in childhood.

- Brain function tests should be performed when fetishism such as that observed in the patient reported here is identified.

- There may be an association between decreased temporal lobe function and fetish behaviour. Long-term monitoring for recurrent fetish behaviour and brain function is required in such patients after treatment. age of 11 years, although he showed no interest in underwear that belonged to his mother, sister and girlfriends. He was an academically strong student. SPECT examination revealed bilaterally decreased cerebral blood flow in the temporal and occipital lobes (figure 1). Other neurological conditions were ruled out, and he was diagnosed with fetishism on the basis of history and examination and successfully treated with behavioural therapy. Klüver-Bucy syndrome is characterised by temporal lobe dysfunction and altered sexual behaviour. ${ }^{3}$ We believe that decreased function of the temporal lobe may have been associated with fetishism in our patient.

Competing interests None.

Patient consent Obtained.

Provenance and peer review Not commissioned; externally peer reviewed.

\section{REFERENCES}

1 Hanada H, Akiyoshi J, Kanehisa M, et al. Hippocampal agenesis in an individual who engaged in violent criminal behaviours after discontinuing carbamazepine and paroxetine treatment. J Forensic Sci 2013:58:255.

2 Mitchell W, Falconer MA, Hill D. Epilepsy with fetishism relieved by temporal lobectomy. Lancet 1954;267:626.

3 Devinsky J, Sacks 0, Devinsky 0. Klüver-Bucy syndrome, hypersexuality, and the law. Neurocase 2010;16:140-5.

Copyright 2014 BMJ Publishing Group. All rights reserved. For permission to reuse any of this content visit

http://group.bmj.com/group/rights-licensing/permissions.

BMJ Case Report Fellows may re-use this article for personal use and teaching without any further permission.

Become a Fellow of BMJ Case Reports today and you can:

- Submit as many cases as you like

- Enjoy fast sympathetic peer review and rapid publication of accepted articles

- Access all the published articles

- Re-use any of the published material for personal use and teaching without further permission

For information on Institutional Fellowships contact consortiasales@bmjgroup.com

Visit casereports.bmj.com for more articles like this and to become a Fellow 